\title{
Adult hippocampal neurogenesis and plasticity in the infrapyramidal bundle of the mossy fiber projection: I. Co-regulation by activity
}

\section{Benedikt Römer ${ }^{1+\neq}$, Julia Krebs ${ }^{1+\neq}$, Rupert W. Overall' ${ }^{1}$, Klaus Fabel ${ }^{1,2}$, Harish Babu $^{1 \dagger}$, Linda Overstreet-Wadiche ${ }^{3}$, Moritz D. Brandt ${ }^{1}$, Robert W. Williams ${ }^{4}$, Sebastian Jessberger ${ }^{5}$ and Gerd Kempermann ${ }^{1,2}$ *}

${ }^{1}$ Genomics of Regeneration, Center for Regenerative Therapies Dresden, Dresden, Germany

${ }^{2}$ German Center for Neurodegenerative Diseases, Partner Institute Dresden, Dresden, Germany

${ }^{3}$ Department of Neurobiology, University of Alabama, Birmingham, AL, USA

${ }^{4}$ Departments of Anatomy and Neurobiology, University of Tennessee Health Science Center, Memphis, TN, USA

${ }^{5}$ Department of Biology, Institute of Cell Biology, Eidgenössische Technische Hochschule Zürich, Zürich, Switzerland

\section{Edited by:}

Steven A. Goldman, University of Rochester Medical Center, USA

Reviewed by:

Steven A. Goldman, University of Rochester Medical Center, USA

Brian R. Christie, University of

Victoria, Canada

\section{*Correspondence:}

Sebastian Jessberger, Department of

Biology, Institute of Cell Biology,

Eidgenössische Technische

Hochschule Zürich, Schafmattstr. 18, 8093 Zürich, Switzerland.

e-mail: jessberger@cell.biol.ethz.ch; Gerd Kempermann, DFG Research

Center for Regenerative Therapies

Dresden, Center for Regenerative

Therapies Dresden, and DZNE,

German Center for

Neurodegenerative Diseases,

Dresden, Tatzberg 47-49, 01307

Dresden, Germany.

e-mail:gerd.kempermann@

crt-dresden.de

${ }^{t}$ Present address:

Benedikt Römer, Department of Psychiatry, Stavanger University

Hospital, Stavanger, Norway;

Julia Krebs, Psychiatric Hospital of

the University of Basel, Basel,

Switzerland;

Harish Babu, Department of

Neurosurgery, Stanford University,

Stanford, CA, USA.

${ }^{\ddagger}$ Benedikt Römer and Julia Krebs

have contributed equally to this work.
Besides the massive plasticity at the level of synapses, we find in the hippocampus of adult mice and rats two systems with very strong macroscopic structural plasticity: adult neurogenesis, that is the lifelong generation of new granule cells, and dynamic changes in the mossy fibers linking the dentate gyrus to area CA3. In particular the anatomy of the infrapyramidal mossy fiber tract (IMF) changes in response to a variety of extrinsic and intrinsic stimuli. Because mossy fibers are the axons of granule cells, the question arises whether these two types of plasticity are linked. Using immunohistochemistry for markers associated with axonal growth and pro-opiomelanocortin (POMC)-GFP mice to visualize the post-mitotic maturation phase of adult hippocampal neurogenesis, we found that newly generated mossy fibers preferentially but not exclusively contribute to the IMF. The neurogenic stimulus of an enriched environment increased the volume of the IMF. In addition, the IMF grew with a time course consistent with axonal outgrowth from the newborn neurons after the induction of neurogenic seizures using kainate. These results indicate that two aspects of plasticity in the adult hippocampus, mossy fiber size and neurogenesis, are related and may share underlying mechanisms. In a second part of this study, published separately (Krebs et al., 2011) we have addressed the question of whether there is a shared genetics underlying both traits.

Keywords: stem cell, hippocampus, learning and memory, depression, schizophrenia

\section{INTRODUCTION}

Subtle differences in hippocampal morphology correlate highly with performance on behavioral tests. The association between hippocampal morphology and hippocampus-dependent function can be observed in many species (Schwegler et al., 1993; Healy et al., 1996; Kempermann et al., 1997; Pleskacheva et al., 2000), including humans (Maguire et al., 2000). Besides the size of the hippocampus itself, the size of the infrapyramidal mossy fiber (IMF) projection, which consists of axons of granule cells in the dentate gyrus that project to pyramidal cells in region CA3, positively correlates with performance in a large variety of behavioral tasks (Schwegler et al., 1981, 1988, 1990; Lipp et al., 1984; Crusio et al., 1987; Roullet and Lassalle, 1990; Schopke et al., 1991; Bernasconi-Guastalla et al., 1994; Laghmouch et al., 1997); for a review see: (Crusio and Schwegler, 2005). Generally, the suprapyramidal mossy fiber (SMF) projection is much larger and more stable than the IMF. The 
immense plasticity of the IMF was noted early on (Schwegler et al., 1981; Crusio et al., 1989). However, the physiological mechanism, why a relatively larger IMF positively correlates with hippocampal function remains unknown. One possible explanation is that SMF form contacts with the apical dendrites of pyramidal cells in CA3, whereas the IMF mainly form synapses on basal dendrites (Blackstad et al., 1970), resulting in input that differs in electrophysiological properties, and information content. Thorny excrescences - the postsynaptic component of the mossy fiber synapse - are closer to the pyramidal cell body on basal dendrites than on apical dendrites (Gonzales et al., 2001), and the proximity of mossy fiber synapses on basal dendrites thus potentially providing a greater influence on somatic membrane potential (Carnevale et al., 1997). Thus, variations of mossy fiber distribution may influence the way in which granule cells drive pyramidal cells in CA3.

The morphological plasticity of the connection between dentate gyrus and CA3 might be more than the reorganization of existing links, because new granule cell neurons are produced throughout life (adult neurogenesis). The new neurons send their axons via the mossy fiber tract to CA3 where they form functional synapses with pyramidal neurons in the characteristic mossy fiber boutons (Zhao et al., 2006; Toni et al., 2008). A potential impact of newborn neurons on the distribution of mossy fibers forming the functionally critical one-way connection exiting the dentate gyrus has not yet been analyzed. Therefore, our questions were whether the two forms of structural plasticity in the adult hippocampus that both correlate with improved performance in hippocampusdependent learning tasks - adult neurogenesis and size of the IMF - might be related.

Our study consisted of two parts, the present one dealing with the question of whether both types of plasticity might actually be identical or are at least co-regulated by activity. The second part, published in a following report addresses potentially shared genetic bases (Krebs et al., 2011).

\section{MATERIALS AND METHODS ANIMALS}

To visualize new neurons using POMC-driven GFP (Overstreet et al., 2004) expression we used two adult transgenic mice. PSANCAM staining was carried out on three adult female C57BL/6 mice. The mice were approximately 6 weeks old.

For the analysis of exposure to an enriched environment on the size of the IMF we used material from our previous study Brandt et al. (2003), in which 6-week-old female C57BL/6 mice had been randomly placed into two experimental conditions: enriched environment (ENR, $N=6)$ and control (CTL, $N=5)$. During the sixth week of living under these experimental conditions, the animals had received daily injections of $\mathrm{BrdU}(50 \mathrm{mg} / \mathrm{kg}$ body weight in sterile $0.9 \%$ saline; Sigma) for five consecutive days. Animals were killed 4 weeks after the last BrdU injection.

In the seizure experiment, we used 48 female, 6 - to 8 -week-old C57BL/6 mice to analyze the size of the mossy fiber projections following seizure activity. Six animals were in each control and seizure groups at $\mathrm{T} 1$ and nine animals were in each control and seizure groups at $\mathrm{T} 2$ and $\mathrm{T} 3$. The animals in the seizure groups received a single intraperitoneal injection of kainic acid (KA; $35 \mathrm{mg} / \mathrm{kg}$ body weight in $0.1 \mathrm{M}$ PBS, Sigma), whereas the animals in the control group were injected with an identical volume of sterile PBS. Between 20 and $45 \mathrm{~min}$ after KA injection the animals began to show convulsive status epilepticus (SE, i.e., forelimb clonus, seesaws, and rearing). SE spontaneously ended 30-60 min after onset. No spontaneous recurrent seizures were observed. One day before being killed, the animals received a single intraperitoneal injection of BrdU.

Mice were killed at three different time points after KA injection (T1: 7 days, T2: 15 days, T3: 28 days) and perfused with $4 \%$ paraformaldehyde.

\section{IMMUNOHISTOCHEMISTRY}

Tissue was prepared as described earlier (Brandt et al., 2003) and coronal brain sections $(40 \mu \mathrm{m})$ for free-floating immunohistochemistry were cut at a table-top sliding microtome. To determine the absolute number of BrdU-labeled and calretinin (CR)expressing cells and to visualize the mossy fiber tract with antisynaptoporin antibodies, we used the peroxidase method (ABC system, Vectastain, Vector Laboratories) with biotinylated anti-rat and anti-rabbit antibodies (1:500; Dianova) and nickel-intensified diaminobenzidine (DAB, Sigma) as chromogen. Immunofluorescent triple labeling was done as described previously (Brandt et al., 2003). As primary antibodies we used rat anti-BrdU (1:500; Harlan Seralab), mouse anti-NeuN (1:100; Chemicon), rabbit anti-calretinin (1:250; Swant), rabbit anti-Synaptoporin (1:50; SynapticSystems), mouse anti-PSA-NCAM (1:400; Chemicon), rabbit anti-GFP (1:250; Molecular Probes), mouse anti-Calbindin (1:250; Swant), rabbit anti-Calbindin (1:100; Swant). Nuclei were visualized using 4'-6-diaminodino-2-phenylindole (DAPI).

\section{CELL COUNTS}

The total number of BrdU-positive and CR-positive cells was assessed in 1-in-6 series of sections [ $240 \mu \mathrm{m}$ apart; experiments 2, 3 , and experiment 4 (T1)] and 1-in-12 series of sections [480 $\mu \mathrm{m}$ apart; experiment 4 (T2 and T3)] from all animals. BrdU-positive cells were counted throughout the rostro-caudal extent of the granule cell layer (GCL) using a $40 \times$ objective (Leica). The optical disector method was modified as described previously in that cells appearing in the uppermost focal plane, when focusing into the section, were not counted (Kempermann and Gage, 1999). The resulting numbers were then multiplied by 6 to obtain the estimated total cell number per granule cell layer.

One-in-twelve series of sections from animals in experiments 2 and 3 were double-labeled for BrdU and NeuN. Fluorescent signals were detected using a spectral confocal microscope (Leica TCS SP2) at room temperature. All analyses were performed in sequential scanning mode to rule out cross-bleeding between channels. Double-labeling was confirmed by three-dimensional reconstructions of $z$ series covering the entire nucleus (or cell) in question. From each animal, 50 BrdU-positive cells randomly picked throughout the granule cell layer were analyzed. Relative numbers were related to the absolute counts of BrdU-positive cells per granule cell layer to yield the absolute numbers of newborn neurons. Images were processed with Adobe Photoshop 7.0, and only general contrast enhancements and color level adjustments were carried out. 


\section{MORPHOMETRIC ANALYSIS}

The size of the hippocampal mossy fiber projections and terminal fields were revealed by an immunohistochemical staining procedure against the presynaptic vesicle protein synaptoporin. Due to its high content of synaptoporin, the mossy fiber tract can be reliably visualized using antibodies against synaptoporin (Singec et al., 2002). Every sixth section was analyzed to assess the size of the hilus, the SMF terminal fields and the IMF (Figure 1). A semiautomated morphometric system (Stereoinvestigator, Microbrightfield, Magdeburg) consisting of a CCD camera (Hitachi) connected to a conventional light microscope (Leica DM-RXE) and a personal computer were used. Mossy fiber fields were outlined from the projected image (magnification: $10 \times$, NA: 0.30 ) and area sizes were determined using the area measurement tool (based on the Cavalieri estimator) of the stereology software Stereo Investigator (MicroBrightField). To obtain the volume of the terminal fields, the sum of areas measured was multiplied by the inverse of the sampling fraction (6) and 40 (the section thickness in micrometer).

\section{STATISTICAL ANALYSES}

All numerical baseline analyses were performed using Statview 5.0.1 for Macintosh or R. For all comparisons ANOVA was performed followed by Fisher's post hoc test, when appropriate. Differences were considered significantly different at a $p<0.05$.

\section{RESULTS \\ AXONS OF NEWBORN NEURONS EXTENDING TOWARD AREA CA3 CONTRIBUTE TO THE IMF}

We used immunohistochemistry to visualize the expression pattern of polysialylated neural cell adhesion molecule (PSA-NCAM) that is specifically expressed in post-mitotic, newborn neurons (Seki and Arai, 1993). In contrast to doublecortin (DCX; Couillard-Despres et al., 2005), another endogenous marker of the newborn neurons, PSA-NCAM is distributed throughout the cell and allows visualization of the entire cell. As expected, PSA-NCAM immunohistochemistry stained immature neurons in the dentate

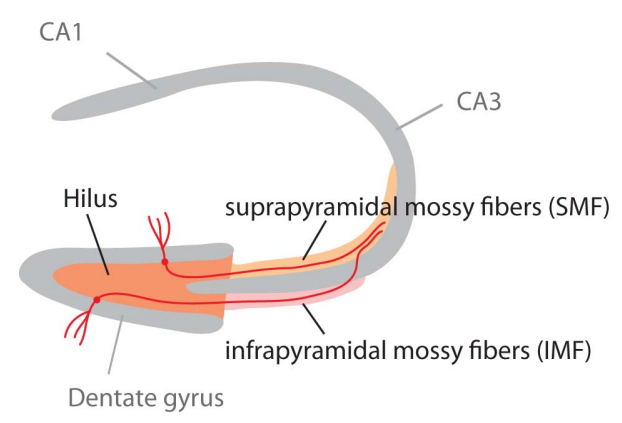

FIGURE 1 | Schematic highlighting the different parts of the mossy fiber projection. The mossy fiber tract consists of the axons of granule cells in the granule cell layer of the dentate gyrus. Adult neurogenesis lifelong generates new granule cells, which (as this study shows) might project through the infrapyramidal blade (IMF) or the suprapyramidal blade (SMF) of the tract. Our question had been, whether new neurons all project through the IMF. This figure is also shown in the publication of part 2 of this study (Krebs et al., 2011). granule cell layer. In addition, PSA-NCAM identified dendrites as well as the axonal processes reaching CA3 (Figure 2A, inset). Many PSA-NCAM positive processes extended through the IMF before crossing the CA3 pyramidal cell layer (Figure 2A). We saw virtually the same distribution pattern of axonal processes extending from new granule cells using transgenic mice expressing EGFP under the control of the POMC promoter (Overstreet et al., 2004). In addition to a strong GFP expression in DCX and PSA-NCAM positive newborn neurons that had been previously described (Overstreet et al., 2004), we found numerous GFP-labeled processes in the IMF (Figure 2B; Overstreet et al., 2004), further suggesting an outgrowth of new axonal processes via the IMF.

We next related the expression pattern of PSA-NCAM and POMC-driven EGFP to the staining pattern for calbindin, a marker expressed by mature granule cells (Sloviter, 1989), and synaptoporin, both visualizing the complete mossy fiber projection (Singec et al., 2002). Whereas the portion of the IMF visualized by PSA-NCAM (Figure 2C) and POMC-driven GFP (Figure 2E) was almost completely congruent with the calbindin and synaptoporin pattern (Figures 2D,F), only a fraction of the SMF projection was detectable with PSA-NCAM or POMC-driven GFP (Figures 2C-F), suggesting that the portion of axonal processes from new neurons might be larger in the IMF than in the SP-MF.

\section{MICE LIVING IN AN ENRICHED ENVIRONMENT HAVE A LARGER IMF}

We next analyzed the size of mossy fiber subfields after physiologic and pathologic stimulation of hippocampal neurogenesis. Environmental enrichment has limited effects on cell proliferation but primarily exerts a survival-promoting effect on the progeny of dividing cells (Kempermann et al., 1997; Kronenberg et al., 2003). Animals in the enriched environment group (ENR) received daily BrdU injections during their sixth week of living in an enriched environment. After the last BrdU injection, these animals lived for another 28 days in their environment. Compared to the control animals (CTR) the ENR mice showed a significant increase in the number of BrdU-positive cells (CTR: 1095.6 \pm 56.97; ENR: $2443 \pm 105 ; p<0.0001$ ) and in the number of newborn neurons (CTL: $866.71 \pm 51.4$; ENR: $2042.18 \pm 91.99 ; p<0.0001)$. Strikingly, the relative proportion of the IMF to the total size of the mossy fiber projection was significantly increased in ENR compared to CTL $(p=0.031)$. No differences between the two groups were found regarding the absolute and relative sizes of the hilus (absolute size: $p=0.744$; relative size: $p=0.8028$ ) and the suprapyramidal layer (absolute size: $p=0.4062$; relative size $p=0.2007$; see Table 1 ). We concluded that the size of the IMF was dynamically regulated by a neurogenic stimulus.

\section{SEIZURES INCREASE CELL PROLIFERATION AND SIZE OF THE IMF}

Seizure activity within the hippocampal formation strongly increases the number of new neurons in the dentate area (Bengzon et al., 1997; Parent et al., 1997; Gray and Sundstrom, 1998; Scott et al., 1998). Thus, we used KA for seizure induction in $\mathrm{C} 57 \mathrm{Bl} / 6$ mice to strongly enhance neurogenesis without leading to massive cell death, supragranular mossy fiber sprouting, or structural reorganization of the hippocampus due to the relatively high resistance of this strain to excitotoxic insults (Schauwecker and 

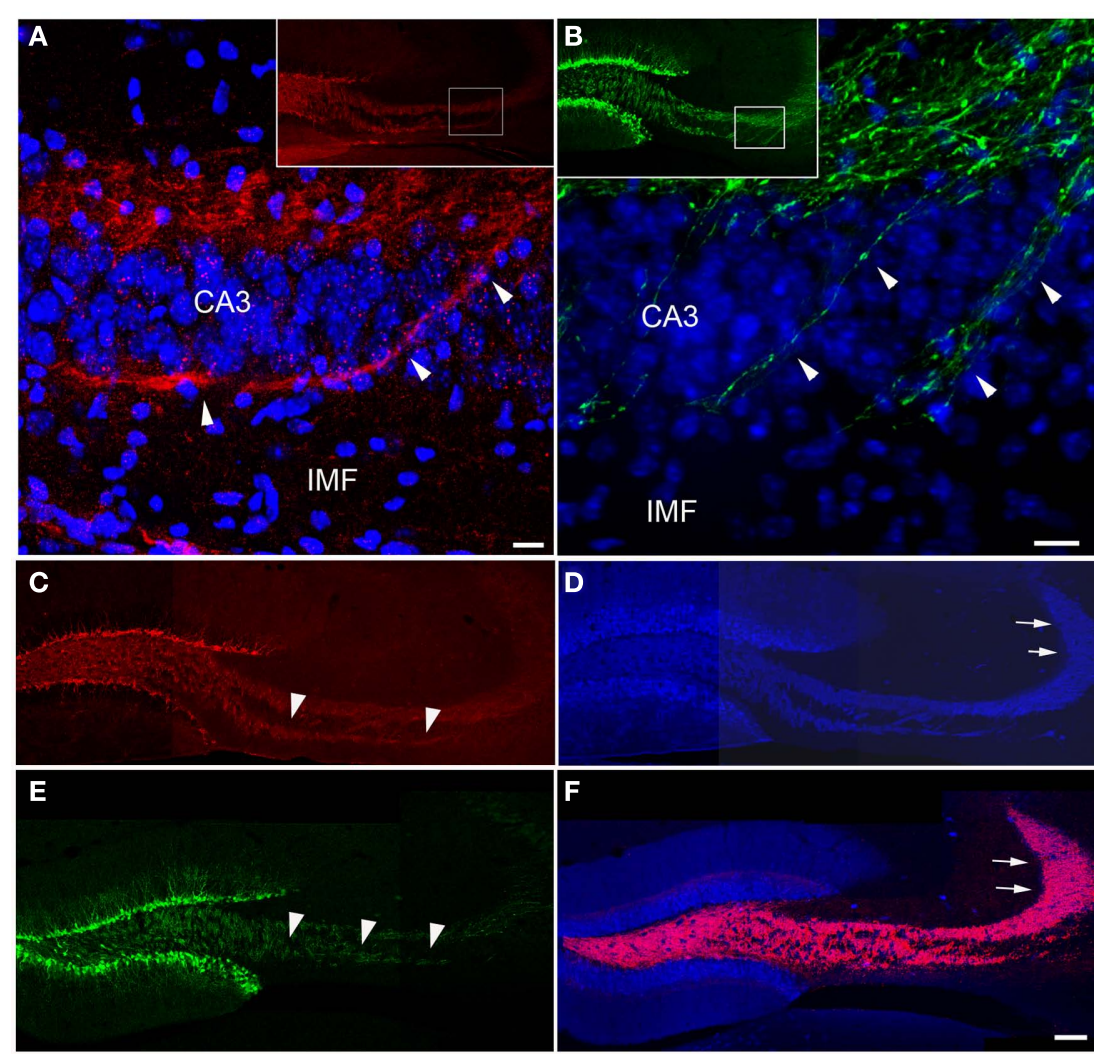

FIGURE 2 | New neurons extend axons via the IMF toward CA3. Axonal processes arising from newborn granule cells that co-label with PSA-NCAM [(A), red] or express POMC-driven GFP [(B), green] labeled a large fraction of the IMF [arrowheads in $(\mathbf{C}, \mathbf{E})$ ] whereas the proportion of axonal processes arising from newborn neurons in the suprapyramidal mossy fiber tract larrows in $(\mathbf{D}, \mathbf{F})]$ - marked by calbindin [(D,F), blue] and synaptoporin staining [(F), red] - was comparatively small. Insets in $(\mathbf{A}, \mathbf{B})$ show an overview of the magnified areas (boxes) in (A,B). Images (C-F) are three single scans using a $20 \times$ objective that were digitally combined. Scale bar in (A,B): $10 \mu \mathrm{m}$, in (F): $100 \mu \mathrm{m}$. CA3, cornu ammonis area 3; IMF, infrapyramidal mossy fibers.

Table 1 | Plasticity of the mossy fiber tract.

\begin{tabular}{|c|c|c|c|c|c|}
\hline \multicolumn{2}{|l|}{ Group } & \multicolumn{4}{|c|}{ Volume of mossy fiber subfields $\left(\mathrm{mm}^{3} \times 10^{-2}\right)$} \\
\hline Control & & $0.985 \pm 0.054$ & $1.330 \pm 0.069$ & $0.437 \pm 0.0203$ & $2.837 \pm 0.120$ \\
\hline \multicolumn{6}{|c|}{ TIMEPOINT AFTER STATUS EPILEPTICUS } \\
\hline 9 days & Control & $1.092 \pm 0.05$ & $1.232 \pm 0.14$ & $0.397 \pm 0.02$ & $2.721 \pm 0.165$ \\
\hline \multirow[t]{2}{*}{15 days } & Control & $0.99 \pm 0.08$ & $1.491 \pm 0.15$ & $0.374 \pm 0.02$ & $2.856 \pm 0.132$ \\
\hline & Seizure & $1.226 \pm 0.10$ & $1.723 \pm 0.06$ & $0.544 \pm 0.03^{* *}$ & $3.493 \pm 0.172^{*}$ \\
\hline \multirow[t]{2}{*}{28 days } & Control & $0.958 \pm 0.08$ & $1.331 \pm 0.12$ & $0.358 \pm 0.02$ & $2.647 \pm 0.173$ \\
\hline & Seizure & $0.922 \pm 0.05$ & $1.621 \pm 0.13$ & $0.460 \pm 0.02 *$ & $3.004 \pm 0.153$ \\
\hline
\end{tabular}

The sizes of the mossy fiber subfields are dynamically regulated with neurogenic stimuli. SP-MF, suprapyramidal mossy fibers; IMF, infrapyramidal mossy fibers; MF, mossy fibers. ${ }^{*} p<0.05,{ }^{*} p<0.001$.

Steward, 1997). To demonstrate a possible correlation between seizure-induced neurogenesis and the size of mossy fiber subfields, animals received at several time points following the injection of $\mathrm{KA}$ one single BrdU injection 1 day before they were killed. Confirming earlier studies, 7 days after the injection of KA the number of BrdU-positive cells in the dentate gyrus had massively increased compared to controls (Figures 3 and 4). We found $764 \pm 30 \mathrm{BrdU}$-positive cells per granule cell layer in control animals and $4623 \pm 659 \mathrm{BrdU}$-positive cells in seizure animals $(p<0.001)$. However, this initial increase in cell proliferation was 

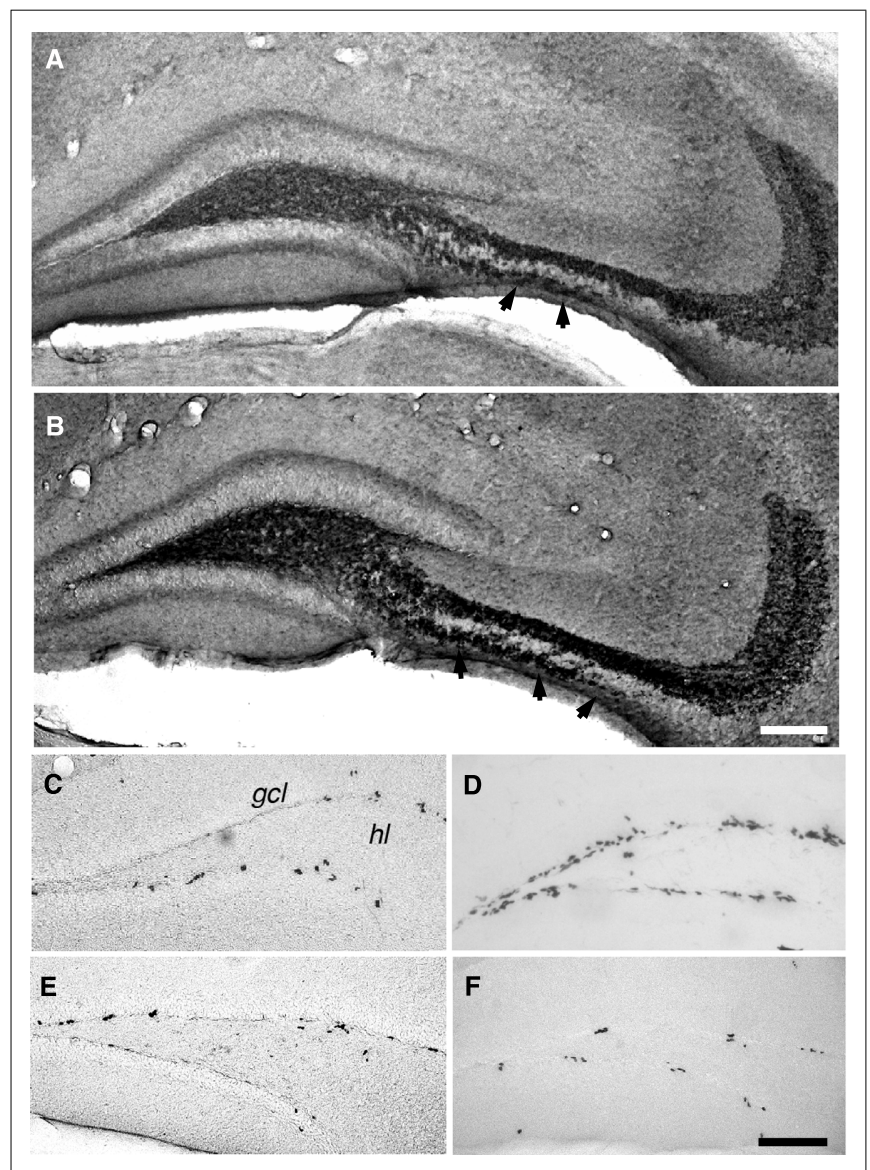

FIGURE 3 | Seizure activity increases neurogenesis and the distribution of mossy fiber subfields. Fifteen days after kainate-induced status epilepticus (B), the mice showed an increase in the IMF compared to control animals $[\mathbf{A}$, arrowheads in $(\mathbf{A}, \mathbf{B})$; anti-synaptoporin staining]. Quantitative assessment of this change is found in Figure 4. Seven days after status epilepticus, a strong increase in the numbers of BrdU-positive cells between seizure (D) and control (C) animals was seen. Proliferation returned to baseline within the second week and showed no significant differences $15(\mathbf{E})$ and 28 (F) days after status epilepticus compared to vehicle-treated controls. Scale bar in (A,F): $100 \mu \mathrm{m}$. gcl, granule cell layer; hl, hilus.

not yet reflected by a significantly increase in the number of early post-mitotic CR-expressing neurons (control animals: $1688 \pm 279$ CR-positive cells per granule cell layer; seizure animals: $2772 \pm 414$ CR-positive cells; $p=0.052)$. Fifteen days after the injection of $\mathrm{KA}$, the proliferative activity in seizure animals had returned to baseline levels (Figures 3 and 4). Control animals had $974 \pm 106$ BrdU-positive cells per GCL and seizure animals had $1194 \pm 230$ $(p=0.4006)$. However, the number of CR-expressing neurons had strongly increased indicating the maturation of previously generated cells into young neurons (Control animals: $3049 \pm 338$; seizure animals: $6020 \pm 272 \mathrm{CR}$-positive cells per granule cell layer; $p<0.0001)$. At the third time point (28 days after KA injection), cell proliferation remained at baseline level, indicating that the effect on cell proliferation was temporally limited. Control animals had $977 \pm 137$ and seizure animals had $1369 \pm 145$ BrdU-positive cells per granule cell layer ( $p=0.10$; Figures 3 and 4 ). At this time

\section{A Dynamics of plastic events after seizure}
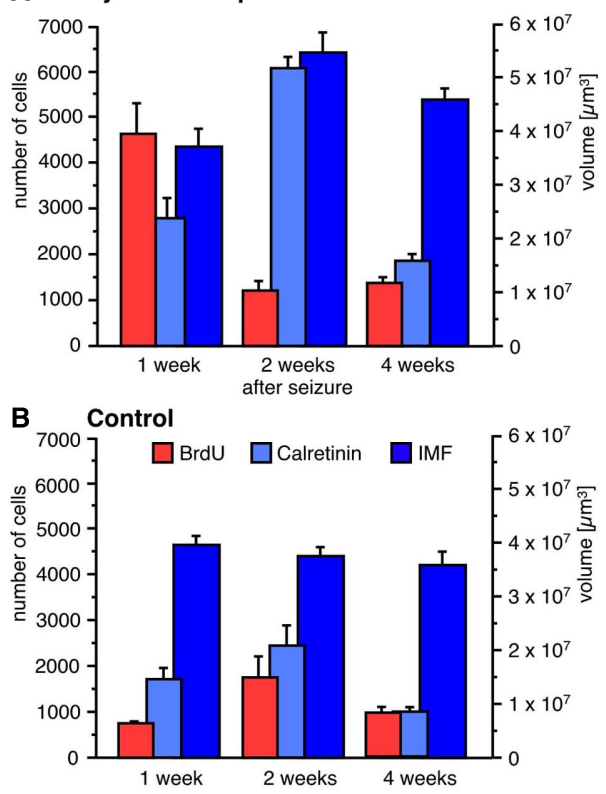

FIGURE 4 | Seizure activity induces neurogenesis and modulates the size of the IMF. A single seizure episode leads to an increase in the number of BrdU-positive cells during the first week after seizure activity but proliferative activity within the dentate area returns to baseline levels after 28 days (A) compared to control animals (B). Newborn cells matured into CR-expressing neurons 14 days after seizures $(\mathbf{A})$ resulting in a significantly bigger size of the IMF (A) compared to controls (B). Twenty-eight days after seizures, the rate of proliferation and the number of early post-mitotic CR-positive neurons had returned to baseline levels whereas the size of the IMF in seizure animals (A) was still significantly enlarged compared to controls (B), suggesting that axonal processes sent from newborn neurons via the IMF remain stable for at least weeks.

point the number of CR-expressing cells had also returned to baseline (1668 \pm 153 in control animals and $1865 \pm 114$ CR-positive cells in seizure animals; $p=0.3203$ ).

To analyze whether the dynamics of seizure-induced neurogenesis is reflected by an increase in the size of the IMF due to an outgrowth of axonal processes from seizure-generated new neurons, we measured the sizes of mossy fiber subfields at three time points after seizure activity. As expected, we did not observe any difference in mossy fiber distribution 7 days after KA injection because seizure-induced cell genesis has not yet generated a significant amount of young neurons with neurites extending toward CA3 (Figure 4). In contrast, 15 days after seizures, we found that the previous increase in cell proliferation ( 7 days after KA) and subsequent increase in immature, CR-expressing neurons had led to a larger IMF, whereas the other mossy fiber subfields remained unchanged (Figures 1 and 4). Twenty-eight days after seizures, the size of the IMF in the seizure animals was still greater compared to controls (Figure 4; Table 1; $p=0.0041$ ), indicating that axonal processes extending from new neurons remain stable for more than 2 weeks.

In summary, we found a dynamic and selective increase in the size of the IMF after a strong neurogenic stimulus. 


\section{DISCUSSION}

In this study we show that the two types of structural plasticity in the hippocampal dentate gyrus, the generation of newborn neurons and the IMF, show signs of co-regulation despite a largely independent genetic control. The axons of newborn neurons also contribute to the most plastic part of the mossy fiber tract the IMF but do not exclusively so.

We found that two neurogenic stimuli, environmental enrichment and seizure activity, influenced mossy fiber distribution and size in the adult hippocampus. Animals living in an enriched environment showed a $20 \%$ increase in the volume of the IMF compared to control animals with an identical genetic background. This finding suggested that the size of the IMF is dynamically influenced by increased neurogenesis. Increased numbers of new granule cells following chemoconvulsant induced seizures (Bengzon et al., 1997; Parent et al., 1997; Jessberger et al., 2007), also indicated that the amount of adult neurogenesis might be linked to IMF size. Injection of KA led to a more than sixfold increase in cell proliferation within the dentate area 7 days after initial seizures. At this early time point after seizures the axonal projections of the immature newborn cells did not lead to changes in mossy fiber distribution, presumably because the new neurons had not yet extended their axons. As predicted, however, we found a strong increase in the volume of the IMF at 15 days after the injection of KA, whereas other subfields did not differ between control and seizure animals. The increase in mossy fibers in the stratum oriens of area CA3 following epileptic activity has been reported before (Represa et al., 1989; Represa and Ben-Ari, 1992), further supporting our idea that axons of newborn neurons contribute to the dynamic changes in IMF after seizure-induced neurogenesis. In any case, our data presented here show that the mossy fiber distribution in adult animals can be dynamically regulated with stimuli that influence the number of newborn neurons such as enriched environment or seizure activity. Although the causal link between adult neurogenesis and mossy fiber plasticity was highly suggestive, our morphological analysis did not show that the new neurons would exclusively form the infrapyramidal projection. The axons of newborn neurons contribute to the IMF but also to the SMF. This pointed toward a potential association but not to an exclusive causal link.

In certain aspects, the maturation of newborn neurons in the adult hippocampus follows mechanisms similar to fetal brain development. The majority of granule cells in the rodent dentate gyrus are generated in two steps: an early phase around E14 and a late phase around P8 (Schlessinger et al., 1975; Altman and Bayer, 1990). Interestingly, the infrapyramidal bundle shows a continuous decrease until postnatal day 45 (Bagri et al., 2003). Thus, the magnitude of the IMF projection during postnatal development supports our finding that the IMF size responds dynamically to the rate of neurogenesis. Consequently, it appears that not all initially established axonal projections and contacts are stable. During development, the initial

\section{REFERENCES}

Aimone, J. B., Wiles, J., and Gage, F. H. (2006). Potential role for adult neurogenesis in the encoding of time in new memories. Nat. Neurosci. 9, 723-727.

\footnotetext{
Altman, J., and Bayer, S. A. (1990). Migration and distribution of two populations of hippocampal progenitors during the perinatal and postnatal periods. J. Comp. Neurol. 301, 365-381.
}

outgrowth of an axon and the formation of synaptic contacts require molecular guidance signals provided by the surrounding tissue (Teuchert-Noodt et al., 2000). After preliminary formation, synaptic contacts undergo profound remodeling. This synaptic or axonal selection depends on excitatory activity (Zhang and Poo, 2001). In the developing mossy fiber system, concomitant preand post-synaptic activity persistently enhanced synaptic strength and maturation (Kasyanov et al., 2004). In fact, the number of surviving new neurons in the adult hippocampus can be manipulated by synaptic activity-inducing learning tasks or environmental enrichment and new neurons appear to participate in certain forms underlying hippocampus-dependent learning and memory (Kempermann et al., 1997; Gould et al., 1999; Drapeau et al., 2007; Dupret et al., 2007, 2008; Kee et al., 2007; Zhang et al., 2008).

Immature, adult-born neurons are notably different for a distinct critical period compared to mature granule cells generated during development (Wang et al., 2000; Esposito et al., 2005; Laplagne et al., 2006; Ge et al., 2007; Garthe et al., 2009). During a period of approximately 2-4 weeks after precursor division in the adult dentate gyrus, newborn neurons show a heightened input resistance, resulting in increased excitability compared to mature granule cells (Schmidt-Hieber et al., 2004; Ge et al., 2007). It has been speculated that this immature yet highly excitable period may be the phase during which new neurons contribute to hippocampal function (Schinder and Gage, 2004; Aimone et al., 2006). It seems that this period coincides with the maturation phase immediately after synaptic contact has been made in CA3 (Toni et al., 2008). From this perspective an association and coregulation of mossy fiber plasticity and adult neurogenesis again seems reasonable.

We reasoned that a straightforward way to explore any partial causative link through a potentially shared genetics. The underlying rationale was that a shared genetic component explaining a notable part of the variance of both traits would establish a meaningful link in the sense of a common genetic causality. However, we failed to identify shared genetics between IMF plasticity and adult neurogenesis (Krebs et al., 2011).

In summary, we here show that the size of the IMF is associated with the levels of adult neurogenesis after neurogenic stimuli, suggesting that newborn neurons shape the morphology of the IMF tract.

\section{ACKNOWLEDGMENTS}

This work was supported by VolkswagenStiftung (to Gerd Kempermann) and NCCR Neural Plasticity and Repair and Swiss National Science Foundation (to Sebastian Jessberger). We would also like to thank Irene Thun, Ruth Zarmstorff, and Silke Kurths for technical support. Benedikt Römer was supported by GRK 238, Deutsche Forschungsgemeinschaft. At the time of this work, Julia Krebs was an associate fellow of International Max Planck Research School LIFE.

Bagri, A., Cheng, H. J., Yaron, A., Pleasure, S. J., and TessierLavigne, M. (2003). Stereotyped pruning of long hippocampal axon branches triggered by retraction inducers of the semaphorin family. Cell 113, 285-299.

Bengzon, J., Kokaia, Z., Elmér, E., Nanobashvili, A., Kokaia, M., and Lindvall, O. (1997). Apoptosis and proliferation of dentate gyrus 
neurons after single and intermittent limbic seizures. Proc. Natl. Acad. Sci. U.S.A. 94, 10432-10437.

Bernasconi-Guastalla, S., Wolfer, D. P., and Lipp, H. P. (1994). Hippocampal mossy fibers and swimming navigation in mice: correlations with size and left-right asymmetries. Hippocampus 4, 53-63.

Blackstad, T. W., Brink, K., Hem, J., and Jeune, B. (1970). Distribution of hippocampal mossy fibers in the rat. An experimental study with silver impregnation methods. J. Comp. Neurol. 138, 433-449.

Brandt, M. D., Jessberger, S., Steiner, B., Kronenberg, G., Reuter, K., BickSander, A., von der Behrens, W., and Kempermann, G. (2003). Transient calretinin expression defines early postmitotic step of neuronal differentiation in adult hippocampal neurogenesis of mice. Mol. Cell. Neurosci. 24, 603-613.

Carnevale, N. T., Tsai, K. Y., Claiborne, B. J., and Brown, T. H. (1997). Comparative electrotonic analysis of three classes of rat hippocampal neurons. J. Neurophysiol. 78, 703-720.

Couillard-Despres, S., Winner, B., Schaubeck, S., Aigner, R., Vroemen, M., Weidner, N., Bogdahn, U., Winkler, J., Kuhn, H. G., and Aigner, L. (2005). Doublecortin expression levels in adult brain reflect neurogenesis. Eur. J. Neurosci. 21, 1-14.

Crusio, W. E., and Schwegler, H. (2005). Learning spatial orientation tasks in the radial-maze and structural variation in the hippocampus in inbred mice. Behav. Brain Funct. 1, 3.

Crusio, W. E., Schwegler, H., and Lipp, H. P. (1987). Radial-maze performance and structural variation of the hippocampus in mice: a correlation with mossy fibre distribution. Brain Res. 425, 182-185.

Crusio, W. E., Schwegler, H., and van Abeelen, J. H. (1989). Behavioral responses to novelty and structural variation of the hippocampus in mice. I. Quantitativegenetic analysis of behavior in the open-field. Behav. Brain Res. 32, 75-80.

Drapeau, E., Montaron, M. F., Aguerre, S., and Abrous, D. N. (2007). Learning-induced survival of new neurons depends on the cognitive status of aged rats. J. Neurosci. 27, 6037-6044.

Dupret, D., Fabre, A., Dobrossy, M. D., Panatier, A., Rodriguez, J. J., Lamarque, S., Lemaire, V., Oliet, S. H., Piazza, P. V., and Abrous, D. N. (2007). Spatial learning depends on both the addition and removal of new hippocampal neurons. PLoS Biol. 5, e214. doi: 10.1371/journal.pone.0005464

Dupret, D., Revest, J. M., Koehl, M., Ichas, F., De Giorgi, F., Costet, P., Abrous, D. N., and Piazza, P. V. (2008). Spatial relational memory requires hippocampal adult neurogenesis. PLOS ONE 3, e1959. doi: 10.1371/journal.pone.0001959

Esposito, M. S., Piatti, V. C., Laplagne, D. A., Morgenstern, N. A., Ferrari, C. C., Pitossi, F. J., and Schinder, A. F. (2005). Neuronal differentiation in the adult hippocampus recapitulates embryonic development. J. Neurosci. 25, 10074-10086.

Garthe, A., Behr, J., and Kempermann, G. (2009). Adult-generated hippocampal neurons allow the flexible use of spatially precise learning strategies. PLoS ONE 4: e5464. doi: 10.1371/journal.pone.0005464

Ge, S., Yang, C. H., Hsu, K. S., Ming, G. L., and Song, H. (2007). A critical period for enhanced synaptic plasticity in newly generated neurons of the adult brain. Neuron 54, 559-566.

Gonzales, R. B., DeLeon Galvan, C. J., Rangel, Y. M., and Claiborne, B. J. (2001). Distribution of thorny excrescences on CA3 pyramidal neurons in the rat hippocampus. J. Comp. Neurol. 430, 357-368.

Gould, E., Beylin, A., Tanapat, P., Reeves, A., and Shors, T. J. (1999). Learning enhances adult neurogenesis in the hippoampal formation. Nat. Neurosci. 2, 260-265.

Gray, W. P., and Sundstrom, L. E. (1998). Kainic acid increases the proliferation of granule cell progenitors in the dentate gyrus of the adult rat. Brain Res. 790, 52-59.

Healy, S. D., Gwinner, E., and Krebs, J. R. (1996). Hippocampal volume in migratory and non-migratory warblers: effects of age and experience. Behav. Brain Res. 81, 61-68.

Jessberger, S., Zhao, C., Toni, N., Clemenson, G. D. Jr., Li, Y., and Gage, F. H. (2007). Seizureassociated, aberrant neurogenesis in adult rats characterized with retrovirus-mediated cell labeling. $J$. Neurosci. 27, 9400-9407.

Kasyanov, A. M., Safiulina, V. F., Voronin, L. L., and Cherubini, E. (2004). GABA-mediated giant depolarizing potentials as coincidence detectors for enhancing synaptic efficacy in the developing hippocampus. Proc. Natl. Acad. Sci. U.S.A. 101, 3967-3972.

Kee, N., Teixeira, C. M., Wang, A. H., and Frankland, P. W. (2007).
Preferential incorporation of adultgenerated granule cells into spatial memory networks in the dentate gyrus. Nat. Neurosci. 10, 355-362.

Kempermann, G., and Gage, F. H (1999). Experience-dependent regulation of adult hippocampal neurogenesis: effects of long-term stimulation and stimulus withdrawal. Hippocampus 9, 321-332.

Kempermann, G., Kuhn, H. G., and Gage, F. H. (1997). More hippocampal neurons in adult mice living in an enriched environment. Nature 386, 493-495.

Krebs, J., Römer, B., Overall, R. W., Fabel, K., Babu, H., Brandt, M., Williams, R. W., Jessberger, S., and Kempermann, G. (2011). Adult hippocampal neurogenesis and plasticity in the infrapyramidal bundle of the mossy fiber projection: II. Genetic covariation and identification of Nos1 as linking candidate gene. Front. Neurosci. 5:106. doi: 10.3389/fnins.2011.00106

Kronenberg, G., Reuter, K., Steiner, B. Brandt, M. D., Jessberger, S., Yamaguchi, M., and Kempermann, G. (2003). Subpopulations of proliferating cells of the adult hippocampus respond differently to physiologic neurogenic stimuli. J. Comp. Neurol. 467, 455-463.

Laghmouch, A., Bertholet, J. Y., and Crusio, W. E. (1997). Hippocampal morphology and open-field behavior in Mus musculus domesticus and Mus spretus inbred mice. Behav. Genet. 27, 67-73.

Laplagne, D. A., Esposito, M. S., Piatti, V. C., Morgenstern, N. A., Zhao, C., van Praag, H., Gage, F. H., and Schinder, A. F. (2006). Functional convergence of neurons generated in the developing and adult hippocampus. PLoS Biol. 4, e409. doi: 10.1371/journal.pbio. 0040409

Lipp, H. P., Schwegler, H., and Driscoll, P. (1984). Postnatal modification of hippocampal circuitry alters avoidance learning in adult rats. Science 225, 80-82.

Maguire, E. A., Gadian, D. G., Johnsrude, I. S., Good, C. D., Ashburner, J., Frackowiak, R. S., and Frith, C. D. (2000). Navigation-related structural change in the hippocampi of taxi drivers. Proc. Natl. Acad. Sci. U.S.A. 97, 4398-4403.

Overstreet, L. S., Hentges, S. T. Bumaschny, V. F., de Souza, F. S., Smart, J. L., Santangelo, A. M., Low, M. J., Westbrook, G. L., and Rubinstein, M. (2004). A transgenic marker for newly born granule cells in dentate gyrus. J. Neurosci. 24, 3251-3259.

Parent, J. M., Yu, T. W., Leibowitz, R. T., Geschwind, D. H., Sloviter, R. S., and Lowenstein, D. H. (1997). Dentate granule cell neurogenesis is increased by seizures and contributes to aberrant network reorganization in the adult rat hippocampus. J. Neurosci. 17, 3727-3738.

Pleskacheva, M. G., Wolfer, D. P., Kupriyanova, I. F., Nikolenko, D. L., Scheffrahn, H., Dell'Omo, G., and Lipp, H. P. (2000). Hippocampal mossy fibers and swimming navigation learning in two vole species occupying different habitats. Hippocampus 10, 17-30.

Represa, A., and Ben-Ari, Y. (1992). Kindling is associated with the formation of novel mossy fibre synapses in the CA3 region. Exp. Brain Res. 92, 69-78.

Represa, A., Le Gall La Salle, G., and BenAri, Y. (1989). Hippocampal plasticity in the kindling model of epilepsy in rats. Neurosci. Lett. 99, 345-350.

Roullet, P., and Lassalle, J. M. (1990). Genetic variation, hippocampal mossy fibres distribution, novelty reactions and spatial representation in mice. Behav. Brain Res. 41, 61-70. Schauwecker, P. E., and Steward, O. (1997). Genetic determinants of susceptability to excitotoxic cell death: implications for gene targeting approaches. Proc. Natl. Acad. Sci. U.S.A. 94, 4103-4108.

Schinder, A. F., and Gage, F. H. (2004). A hypothesis about the role of adult neurogenesis in hippocampal function. Physiology (Bethesda) 19, 253-261.

Schlessinger, A. R., Cowan, W. M., and Gottlieb, D. I. (1975). An autoradiographic study of the time of origin and the pattern of granule cell migration in the dentate gyrus of the rat. J. Comp. Neurol. 159, 149-175.

Schmidt-Hieber, C., Jonas, P., and Bischofberger, J. (2004). Enhanced synaptic plasticity in newly generated granule cells of the adult hippocampus. Nature 429, 184-187.

Schopke, R., Wolfer, D. P., Lipp, H. P., and Leisinger-Trigona, M. C. (1991). Swimming navigation and structural variations of the infrapyramidal mossy fibers in the hippocampus of the mouse. Hippocampus 1 , 315-328.

Schwegler, H., Crusio, W. E., and Brust, I. (1990). Hippocampal mossy fibers and radial-maze learning in the mouse: a correlation with spatial working memory but not with nonspatial reference memory. Neuroscience 34, 293-298. 
Schwegler, H., Crusio, W. E., Lipp, H. P., and Heimrich, B. (1988). Watermaze learning in the mouse correlates with variation in hippocampal morphology. Behav. Genet. 18, 153-165.

Schwegler, H., Lipp, H. P., Van der Loos, H., and Buselmaier, W. (1981). Individual hippocampal mossy fiber distribution in mice correlates with two-way avoidance performance. Science 214, 817-819.

Schwegler, H., Mueller, G. G., Crusio, W. E., Szemes, L., and Seress, L. (1993). Hippocampal morphology and spatially related behavior in LongEvans and CFY rats. Hippocampus 3, $1-7$.

Scott, B. W., Wang, S., Burnham, W. M., De Boni, U., and Wojtowicz, J. M. (1998). Kindling-induced neurogenesis in the dentate gyrus of the rat. Neurosci. Lett. 248, 73-76.

Seki, T., and Arai, Y. (1993). Highly polysialylated neural cell adhesion molecule (NCAM-H) is expressed by newly generated granule cells in the dentate gyrus of the adult rat. J. Neurosci. 13, 2351-2358.

Singec, I., Knoth, R., Ditter, M., Hagemeyer, C. E., Rosenbrock, H., Frotscher, M., and Volk, B. (2002). Synaptic vesicle protein synaptoporin is differently expressed by subpopulations of mouse hippocampal neurons. J. Comp. Neurol. 452, 139-153.

Sloviter, R. S. (1989). Calcium-binding protein (calbindin-D28k) and parvalbumin immunocytochemistry: localization in the rat hippocampus with specific reference to the selective vulnerability of hippocampal neurons to seizure activity. J. Comp. Neurol. 280, 183-196.

Teuchert-Noodt, G., Dawirs, R. R., and Hildebrandt, K. (2000). Adult treatment with methamphetamine transiently decreases dentate granule cell proliferation in the gerbil hippocampus. J. Neural Transm. 107, 133-143.

Toni, N., Laplagne, D. A., Zhao, C., Lombardi, G., Ribak, C. E., Gage, F. H., and Schinder, A. F. (2008). Neurons born in the adult dentate gyrus form functional synapses with target cells. Nat. Neurosci. 11, 901-907.

Wang, S., Scott, B. W., and Wojtowicz, J. M. (2000). Heterogenous properties of dentate granule neurons in the adult rat. J. Neurobiol. 42, 248-257.

Zhang, C. L., Zou, Y., He, W., Gage, F. H., and Evans, R. M. (2008). A role for adult TLX-positive neural stem cells in learning and behaviour. Nature 451, 1004-1007.

Zhang, L. I., and Poo, M. M. (2001). Electrical activity and development of neural circuits. Nat. Neurosci. 4 (Suppl.), 1207-1214.

Zhao, C., Teng, E. M., Summers, R. G. Jr., Ming, G. L., and Gage, F. H. (2006). Distinct morphological stages of dentate granule neuron maturation in the adult mouse hippocampus. J. Neurosci. 26, 3-11.

Conflict of Interest Statement: The authors declare that the research was conducted in the absence of any commercial or financial relationships that could be construed as a potential conflict of interest.

Received: 17 December 2010; accepted: 29 August 2011; published online: 27 September 2011.

Citation: Römer B, Krebs J, Overall RW, Fabel $K$, Babu H, Overstreet-Wadiche $L$, Brandt MD, Williams RW, Jessberger $S$ and Kempermann G (2011) Adult hippocampal neurogenesis and plasticity in the infrapyramidal bundle of the mossy fiber projection: I. Co-regulation by activity. Front. Neurosci. 5:107. doi: 10.3389/fnins.2011.00107

This article was submitted to Frontiers in Neurogenesis, a specialty of Frontiers in Neuroscience.

Copyright ๑ 2011 Römer, Krebs, Overall, Fabel, Babu, Overstreet-Wadiche, Brandt, Williams, Jessberger and Kempermann. This is an open-access article subject to a non-exclusive license between the authors and Frontiers Media $S A$, which permits use, distribution and reproduction in other forums, provided the original authors and source are credited and other Frontiers conditions are complied with. 